\title{
Impact of Shielding and First Dose of COVID-19 Vaccination in Kidney Transplant Recipients
}

\author{
Rachel J. Middleton ${ }^{a}$ Julie Gorton ${ }^{a}$ Edmond O'Riordan ${ }^{a}$ Sean Knight ${ }^{b}$ \\ Philip A Kalra ${ }^{c}$ Dimitrios Poulikakos ${ }^{a}$ \\ aRenal Services, Salford Royal NHS Foundation Trust, Salford, UK; bUniversity of Manchester, Manchester, UK; \\ 'Director of Research and Innovation, Northern Care Alliance, Salford Royal NHS Foundation Trust, Salford, UK
}

\section{Dear Editor,}

We read with interest Riella et al.'s [1] article highlighting the importance of focused studies to optimise the protection of kidney transplant recipients (KTR) during the COVID-19 pandemic. We present data from our kidney transplant service regarding the effect of shielding upon COVID-19 incidence and the antibody response following the first dose of COVID-19 vaccination in our KTR.

In our population of $698 \mathrm{KTR}$ in the north west of England, we have had 76 (10.9\% of all KTR) symptomatic cases of COVID-19 diagnosed with nasopharyngeal RTPCR over a period of 13 months from March 2020, with a COVID-19-related mortality rate of $22 \%$. During the 3 months when shielding advice was paused (August to October 2020), 28 (36.8\%) patients had COVID-19 infection, with 22 (78.5\%) of these diagnosed in October 2020 (Fig. 1) when the regional community incidence of COVID-19 was 529.5 cases/10,0000.

We performed COVID-19 antibody testing in 298 KTR during routine phlebotomy appointments prior to vaccination between December 2020 and February 2021. COVID-19 antibody testing was undertaken using the Public Health England-approved Siemens immunoassay,

karger@karger.com www.karger.com/nef

Karger"
C 2021 The Author(s).

Published by S. Karger AG, Basel

This is an Open Access article licensed under the Creative Commons Attribution-NonCommercial-4.0 International License (CC BY-NC) (http://www.karger.com/Services/OpenAccessLicense), applicable to the online version of the article only. Usage and distribution for commercial purposes requires written permission. detecting antibodies targeting the spike protein S1 RBD [2].

There were 55 out of 298 (18.4\%) KTR with detectable COVID-19 antibodies prior to vaccination and 35 (63\%) had previous asymptomatic disease. Of the $243 \mathrm{KTR}$ with no detectable antibodies prior to vaccination, $70 \mathrm{KTR}$ have also had antibody testing $>12$ days after their first COVID-19 vaccination (mean 40 days post-vaccination, range $12-79$ days). Of these, only 16 (22.9\%) developed detectable COVID-19 antibodies following the first dose vaccination (mean 38 days post-vaccination, range 14-64 days). Fifty-seven patients received mRNA vaccine (Pfizer BioNTech) and 11 received the adenovirus platform (Astra Zeneca Oxford) vaccine, and the vaccine platform was unknown in a further 2 patients. Eight KTR were diagnosed with COVID-19 infection more than 7 days following their first vaccine.

Our data confirm the high mortality associated with COVID-19 in KTR and highlights the need to shield when the prevalence of COVID-19 in the community is high. The low antibody response is concerning and consistent with data from Boyarsky et al. [3] in which only $17 \%$ of KTR reported detectable antibody response after 


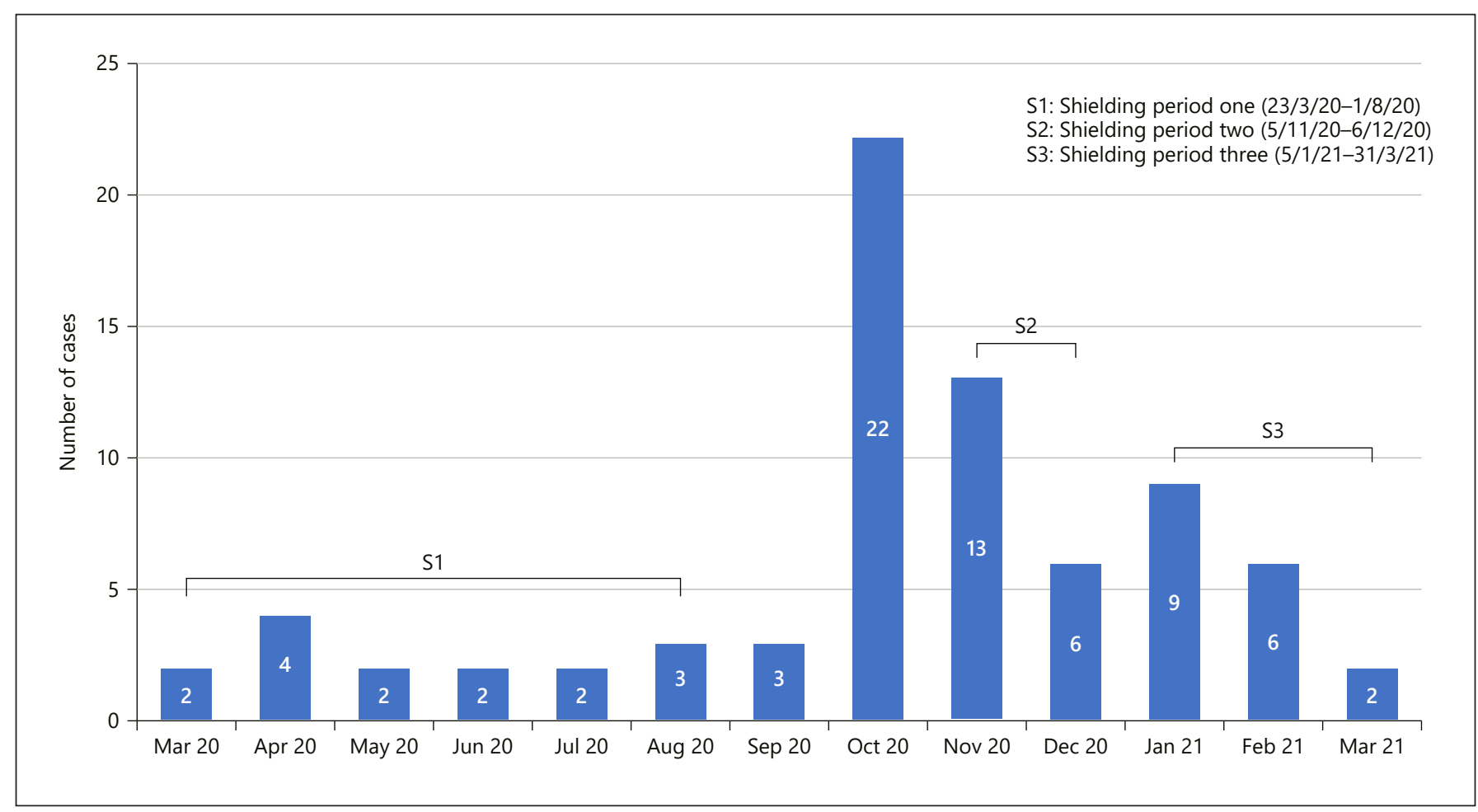

Fig. 1. Number of COVID-19 cases in kidney transplant recipients per month and periods of shielding in the UK.

a single COVID-19 vaccination dose. Our population similarly were predominantly taking tacrolimus and mycophenolate immunosuppression. Despite the promising vaccine effectiveness in the general population, KTR receiving immunosuppression are less likely to achieve an antibody response to COVID-19 vaccination following the first dose. Although these are only preliminary data, and we can expect further seroconversion following the second dose of vaccine assuming our 12 week vaccination schedule is consistent with Boyarsky et al.'s [4] updated results, further research is required to explore effective strategies to decrease the risk of infection from COVID-19 in this vulnerable population and to ascertain the best vaccine dosing schedule to maximise antibody protection in immunosuppressed KTR.

\section{Statement of Ethics}

This study is exempt from ethical committee approval as the authors presented a retrospective study of the transplant population with all samples collected as part of routine care.

\section{Conflict of Interest Statement}

Professor Kalra has honoraria and consultation fees from Vifor, Astra Zeneca, Napp, Pharmacosmos, Bayer, and UCB, and research grants from Vifor, Astellas, BergenBio, and Evotec.

\section{Funding Sources}

This was an evaluation of patients as part of their routine clinical care and no additional costs were incurred.

\section{Author Contributions}

Rachel Middleton has participated in study design, data collection, analysis, and writing of the paper. Julie Gorton has participated in data collection. Dimitrios Poulikakos has contributed to the study design and writing of the paper. Sean Knight, Edmond O'Riordan, and Philip Kalra participated in writing of the paper.

\section{Data Availability Statement}

Data from this paper are not available for public use. 


\section{References}

1 Riella LV, Azzi JR, Cravedi P. Preventing coronavirus disease 2019 in kidney transplant recipients: where should we begin? Nephron. 2021 Mar 31;145(3):280-4

2 Public Health England. Evaluation of sensitivity and specificity of four commercially available SARS-CoV-2 antibody immunoassays. 2020. Available from: https://assets.publishing.service.gov.uk/ Accessed 2020 Nov 20.
3 Boyarsky BJ, Werbel WA, Avery RK, Tobian AAR, Massie AB, Segev DL, et al. Immunogenicity of a single dose of sars-cov- 2 messenger rna vaccine in solid organ transplant recipients. JAMA. 2021;325(17):1784-6.

4 Boyarsky BJ, Werbel WA, Avery RK, Tobian AAR, Massie AB, Segev DL, et al. Antibody response to 2-dose sars-cov-2 mrna vaccine series in solid organ transplant recipients. JAMA. 2021 Jun 1;325(21):2204-6.
Middleton/Gorton/O’Riordan/Knight/ Kalra/Poulikakos 